\title{
Produção de maracujazeiro-amarelo sob diferentes densidades de plantio ${ }^{(1)}$
}

\author{
Valter Carvalho de Andrade Júnior(2), Sebastião Elviro de Araújo Neto(3) \\ José Carlos Moraes Rufini(4) e José Darlan Ramos ${ }^{(3)}$
}

\begin{abstract}
Resumo - O adensamento de plantas em cultivos do maracujazeiro-amarelo é importante por propiciar maior rentabilidade em menor área. O objetivo deste trabalho foi avaliar o efeito de diferentes densidades de plantio na produção, qualidade dos frutos e rentabilidade do maracujazeiro-amarelo. O experimento foi instalado e conduzido em pomar comercial da Fazenda Sant'ana, Município de São Tiago, MG. O delineamento experimental utilizado foi o de blocos casualizados com cinco tratamentos e quatro repetições. Os tratamentos constituíram-se de diferentes espaçamentos na linha de plantio: T1, 1,0 m (3.330 plantas/ha); T2, 1,5 m (2.220 plantas/ha); T3, 2,0 m (1.660 plantas/ha); T4, 3,0 m (1.100 plantas/ha) e T5, 4,0 m (830 plantas/ha). O espaçamento entre linhas foi de 3,0 m em todos os tratamentos. Cada parcela foi constituída de $12 \mathrm{~m}$ de comprimento por $3,0 \mathrm{~m}$ de largura $\left(36 \mathrm{~m}^{2}\right)$. O plantio foi realizado em outubro de 2001, e a colheita, a partir de abril, estendendo-se até agosto de 2002. A maior produtividade foi estimada em 11,9 t/ha na densidade de 1.841 plantas/ha. $\mathrm{O}$ adensamento não altera a qualidade do fruto. A máxima eficiência econômica foi alcançada na densidade de 1.340 plantas/ha, com rentabilidade de $\mathrm{R} \$ 1.321,92 / \mathrm{ha}$.
\end{abstract}

Termos para indexação: Passiflora edulis, produtividade, qualidade, rentabilidade, população vegetal.

\section{Production of yellow passion fruit under different planting densities}

\begin{abstract}
The density of plants in cultivations of yellow passion fruits is important, because it provides larger profitability in smaller areas. The objective of this research was to evaluate the effect of different planting densities on production, quality of fruit and profitability of yellow passion fruit. The experiment was installed in a commercial orchard in Sant'ana Farm, district of São Tiago, MG, Brazil. The experimental design was in randomized blocks with five treatments and four replications. The treatments were different planting densities: T1, $1.0 \mathrm{~m}$ (3,330 plants/ha); T2, $1.5 \mathrm{~m}$ (2,220 plants/ha); T3, $2.0 \mathrm{~m}$ (1,660 plants/ha); T4, $3.0 \mathrm{~m}$ (1,100 plants/ha) and T5, $4.0 \mathrm{~m}$ (830 plants/ha). The distance between the lines was $3.0 \mathrm{~m}$ to all the treatments. Each plot was $12 \mathrm{~m}$ long and $3.0 \mathrm{~m}$ wide $\left(36 \mathrm{~m}^{2}\right)$. The planting was accomplished in October of 2001. The harvest began in April extending to August of 2002. The largest productivity was 11.9 ton/ha at a density of 1,841 plants/ha. Planting density did not change the quality of the fruits. The largest economical efficiency was reached under the density of 1,340 plants/ha, with a profitability of $\mathrm{R} \$ 1,321.92 / \mathrm{ha}$.
\end{abstract}

Index terms: Passiflora edulis, productivity, quality, profitability, plant population.

\section{Introdução}

A importância da cultura do maracujazeiro (Passiflora edulis Sims.f. flavicarpa Deg.) no Brasil

(1) Aceito para publicação em 21 de outubro de 2003.

(2) Universidade Vale do Rio Verde de Três Corações, Avenida Castelo Branco, 82, Bairro Chácara das Rosas, CEP37410-000 Três Corações, MG. E-mail: valterjr@mgconecta.com.br

(3) Universidade Federal de Lavras, Caixa Postal 37, CEP 37200-000 Lavras, MG. E-mail: selviro@zipmail.com.br, darlan@ufla.br

(4) Universidade Vale do Rio Doce, Rua Israel Pinheiro, 2000 CEP 35020220 Governador Valadares, MG. E-mail: jcrufini@mgconecta.com.br está no volume produzido, e no emprego de mão-deobra no campo, avaliado entre 112 a 272 dias homem/ha/ano (Pires \& São José, 1994; Agrianual, 2002), pelo fato de a colheita ser manual e semanal. Ocorre também geração de emprego na indústria e nos serviços de comercialização, pois o suco de maracujá é o terceiro mais produzido no Brasil (Aguiar \& Santos, 2001), e, além disso, o manejo da cultura é adequado para pequenas propriedades (Agrianual, 1999).

Apesar da sua relevância, houve pouco avanço na produção dessa cultura entre 1990 e 2000. A área plantada cresceu apenas $33,4 \%$, mas com decréscimo de $20,8 \%$ na produtividade, que passou de 
12,5 t/ha em 1990 para 9,9 t/ha em 2000 (IBGE, 2002). O potencial produtivo do maracujazeiro, entretanto, é bem maior, podendo alcançar até $65,21 \mathrm{t} / \mathrm{ha}$, com a utilização de genótipos superiores, como o híbrido IAC-3 (Meletti et al., 2000).

A falta de informações sobre a cultura no Município de São Tiago, MG, pode ser um fator limitante a sua exploração. A cultura vem sendo conduzida com o emprego de sistemas de produção desenvolvidos em outras regiões havendo, deste modo, necessidade do estabelecimento de tecnologias adaptadas a características locais. A densidade de plantas na linha de plantio é um dos fatores que interfere na eficiência técnica e econômica. $\mathrm{O}$ adensamento de plantio em maracujazeiro permite maior produtividade nas primeiras safras, porém, a produtividade deve ser acompanhada de maior retorno econômico.

No Brasil, diversos trabalhos revelaram resultados significativos do adensamento de até 5.000 plantas/ha, correspondendo ao espaçamento de 2,0x1,0 m (Pace \& Araújo, 1981), atingindo produtividade de $33,1 \mathrm{t} /$ ha na primeira safra. Andrade et al. (1994) constataram que o espaçamento $3,0 \times 1,5 \mathrm{~m}$ produziu, na safrinha, $14,5 \mathrm{t} / \mathrm{ha}, 219 \%$ a mais que o maior espaçamento (3,0x6,0 m). São José (1998) recomenda plantio com espaçamento de 3,5x1,75 m, e potencial produtivo de $20 \mathrm{t} / \mathrm{ha}$. Porém, alguns trabalhos não apresentaram efeito significativo, como os de Cereda \& Vasconcelos (1991), cuja produtividade média foi de $26,4 \mathrm{t} /$ ha e densidade variando de $833 \mathrm{a}$ 3.333 plantas/ha, e Manica et al. (1989), com produtividade média de $12,8 \mathrm{t} / \mathrm{ha}$, em densidade variando de 695 a 2.000 plantas/ha. Além disso, a maior produtividade obtida com o adensamento pode não proporcionar maior retorno econômico (Kits et al., 1996).

O objetivo deste trabalho foi avaliar o efeito de diferentes densidades de planta na produção, qualidade dos frutos e rentabilidade do maracujazeiroamarelo.

\section{Material e Métodos}

O experimento foi realizado em pomar comercial, da Fazenda Sant'ana, Município de São Tiago, MG (44³6' Oeste e $20^{\circ} 54^{\prime}$ Sul). O delineamento experimental utilizado foi o de blocos casualizados, com cinco tratamentos e quatro repetições. Os tratamentos constituíram-se de diferentes espaçamentos na linha de plantio: T1, 1,0 m
(3.330 plantas/ha); T2, $1,5 \mathrm{~m}$ (2.220 plantas/ha); T3, 2,0 m (1.660 plantas/ha); T4, 3,0 m (1.100 plantas/ha) e T5, 4,0 m ( 830 plantas/ha). Cada parcela teve $12 \mathrm{~m}$ de comprimento por $3,0 \mathrm{~m}$ de largura $\left(36 \mathrm{~m}^{2}\right)$. $\mathrm{O}$ espaçamento entre linhas foi de $3,0 \mathrm{~m}$. O plantio foi realizado em outubro de 2001, utilizando-se mudas provenientes de tubetes, plantadas com aproximadamente $20 \mathrm{~cm}$ de altura, em covas de $0,40 \times 0,40 \times 0,40 \mathrm{~m}$. A correção da acidez e a adubação foram realizadas com base na análise química do solo com as adubações de plantio na cova, aplicando-se $880 \mathrm{~kg} / \mathrm{ha}$ de superfosfato simples e $220 \mathrm{~kg} / \mathrm{ha}$ de calcário dolomítico. Foram aplicados $20 \mathrm{~g}$ de sulfato de zinco, $10 \mathrm{~g}$ de ácido bórico e $20 \mathrm{~L}$ de esterco de curral por planta. As adubações de formação e produção, a condução e os demais tratos culturais seguiram as recomendações de Ruggiero et al. (1996) e Quaggio \& Piza Júnior (1998), porém, sem polinização artificial. A colheita iniciou-se em abril, estendendo-se até agosto de 2002. Foram realizadas duas colheitas por semana, e colhidos os frutos caídos no solo e os maduros na planta. Avaliaram-se as produções totais da parcela, que serviram para estimar a produtividade (t/ha), o número de frutos por planta e o peso médio dos frutos.

No final, coletou-se uma amostra representativa de frutos de cada parcela para avaliação de suas características: rendimento de polpa (arilo + semente) e de suco (\%); sólidos solúveis, determinado em refratômetro digital com compensação automática de temperatura; acidez total titulável, determinada pela titulação de um extrato $(1 \mathrm{~mL}$ de suco/50 mL água destilada), com hidróxido de sódio $(\mathrm{NaOH}, 0,1 \mathrm{~N})$, expresso em porcentagem de ácido cítrico.

A rentabilidade econômica foi calculada pela diferença entre o lucro bruto e o custo total de cultivo, resultando em lucro líquido. Os custos foram calculados com base nos gastos de cada sistema de cultivo (espaçamento), possibilitando obter o cálculo do custo de produção em função do espaçamento adotado.

\section{Resultados e Discussão}

Houve diferenças estatísticas entre os tratamentos em relação à produtividade, número de frutos por planta e rentabilidade econômica.

A relação entre a produtividade e as diferentes densidades de plantio foi quadrática, com ponto de máxima de 11,9 t/ha, na densidade de 1.841 plantas/ha, que corresponde ao espaçamento de $3,0 \times 1,8 \mathrm{~m}$ (Figura 1). Já a relação entre o número de frutos por planta e as diferentes densidades foi linear inversa $(\mathrm{Fi}$ gura 2). 
O aumento da densidade de plantio elevou a produção numa correlação direta com o acréscimo de frutos por área, apesar de o número de frutos por planta ser significativamente menor. $\mathrm{O}$ menor número de frutos por planta pode estar relacionado com o menor número de flores, causado pelo alto sombreamento das plantas adensadas. Apesar de o sombreamento ter causado maior competição entre os frutos, não houve alteração significativa no peso médio, o que colaborou para manter a diferença na

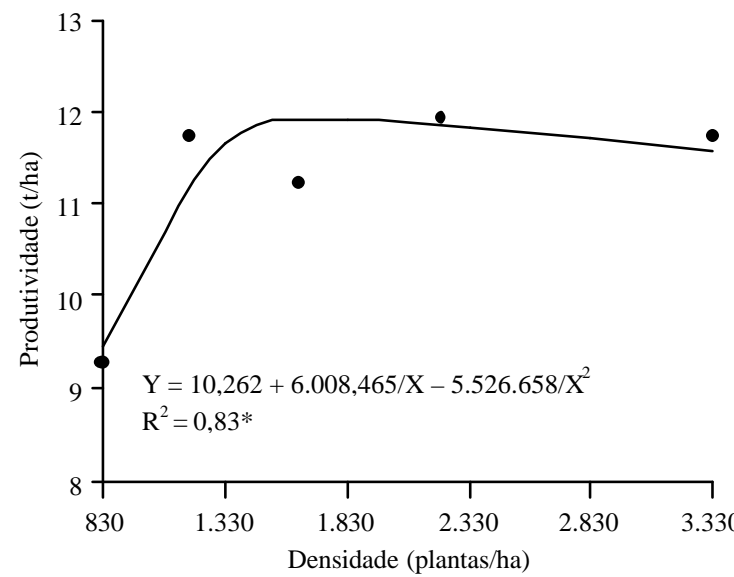

Figura 1. Produtividade do maracujazeiro-amarelo sob diferentes densidades de plantio, em São Tiago, MG.

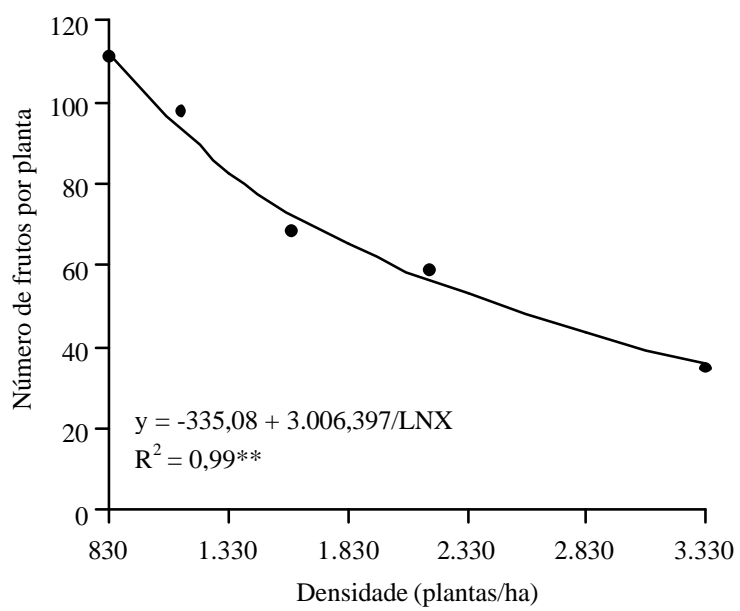

Figura 2. Número de frutos por planta do maracujazeiroamarelo em diferentes densidades de plantio, em São Tiago, MG. produção total por área, resultado semelhante ao observado por Manica et al. (1989).

O aumento do espaçamento na linha de plantio diminui a sobreposição de ramos até um ponto em que não mais interfere no desenvolvimento e produção de plantas; neste caso foi de 1.841 plantas/ha no espaçamento de 3,0x1,8 m. Assim, sob essa configuração, pode-se esperar o máximo da capacidade produtiva permitida pela constituição genética das plantas e pelas condições do experimento, não havendo mais ganho de produção com aumento dos espaçamentos (Ritzinger et al., 1987).

$\mathrm{O}$ adensamento de plantio do maracujazeiro não interferiu na qualidade do fruto (Tabela 1). Resultados semelhantes foram observados por Andrade et al. (1994) e Vasconcelos \& Andrade (1998).

$\mathrm{O}$ adensamento de plantas não afetou o peso médio dos frutos e está de acordo com os resultados obtidos por Pace \& Araújo (1981), Lederman et al. (1986), Ritzinger et al. (1987), Cereda \& Vasconcelos (1991), Andrade et al. (1994) e Manica et al. (1994).

No plantio adensado, a área foliar por planta não aumenta, proporcionalmente, em relação ao número de plantas, além disso, o sombreamento de ramos diminui a área foliar que serve de fonte, e aumenta a área foliar que serve de dreno. Portanto, existe uma relação entre a área foliar disponível (fonte) e o número de frutos de uma planta, que está diretamente relacionado com o tamanho e peso dos frutos (Forshey \& Elfving, 1977). Porém, o peso médio do fruto de maracujazeiro não é uma boa variável a ser avaliado em trabalhos como este, pois existe grande variabilidade no tamanho do fruto na mesma planta e

Tabela 1. Qualidade dos frutos da safrinha de maracujazeiro-amarelo cultivado, em diferentes densidades de plantio, em São Tiago, $\mathrm{MG}^{(1)}$

\begin{tabular}{ccrcccc}
\hline $\begin{array}{c}\text { Espacamento (m) } \\
\text { (linha x planta) }\end{array}$ & Plantas/ha & $\begin{array}{c}\text { PMF } \\
(\mathrm{g})\end{array}$ & $\begin{array}{c}\text { Polpa } \\
(\%)\end{array}$ & $\begin{array}{c}\text { Suco } \\
(\%)\end{array}$ & $\begin{array}{c}\text { SS } \\
(\%)\end{array}$ & $\begin{array}{c}\text { ATT } \\
(\%)\end{array}$ \\
\hline $3,0 \times 1,0$ & 3.330 & 99,73 & 50,99 & 35,09 & 16,33 & 5,25 \\
$3,0 \times 1,5$ & 2.220 & 99.08 & 55,94 & 38,50 & 15,90 & 4,73 \\
$3,0 \times 2,0$ & 1.660 & 100.88 & 52,48 & 34,46 & 16,58 & 4,31 \\
$3,0 \times 3,0$ & 1.100 & 108,78 & 53,17 & 34,63 & 16,94 & 4,73 \\
$3.0 \times 4.0$ & 830 & 102.75 & 50.27 & 34.32 & 17,29 & 4.60 \\
\hline Média & - & 101.84 & 52,57 & 35,40 & 16,61 & 4,72 \\
CV (\%) & - & 5.21 & 10,20 & 13,19 & 4,23 & 11,11 \\
(1)Não houve diferenças significativas, a 5\%, pelo teste Fem nenhuma das \\
variáveis avaliadas; PMF: peso médio do fruto; SS: sólidos solúveis; \\
ATT: acidez total titulável.
\end{tabular}


mesmo genótipo (Nascimento et al., 2003), podendo mascarar diferenças no crescimento dos mesmos entre os tratamentos.

O rendimento econômico se ajustou a uma equação polinomial de função quadrática, com ponto de máxima em 1.340 plantas/ha, equivalente ao espaçamento de 3,0×2,5 m, o qual proporcionou uma rentabilidade de $\mathrm{R} \$ 1.321,92 /$ ha (Figura 3 ). Neste caso, a maior eficiência técnica não coincidiu com a maior eficiência econômica, por causa dos custos maiores do plantio adensado.

Os insumos e mão-de-obra foram os principais responsáveis pelo aumento dos custos de produção no plantio adensado. Os insumos variaram de $\mathrm{R} \$ 2.017,07$ a R \$ 2.618,07 e a mão-de-obra, de $\mathrm{R} \$ 934,33$ a $\mathrm{R} \$ 1.170,00$, do maior para o menor espaçamento (Tabela 2). Quanto aos insumos, dois

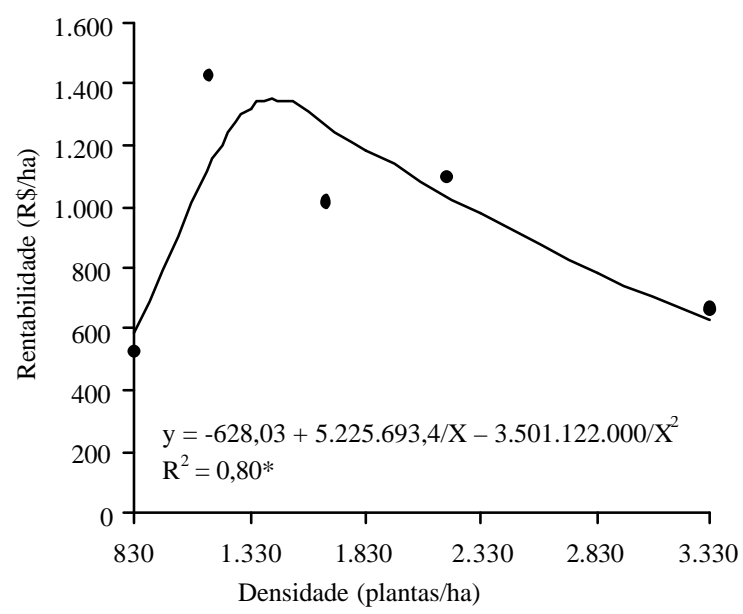

Figura 3. Rentabilidade do maracujazeiro-amarelo sob diferentes densidades de plantio, em São Tiago, MG. itens foram significativamente determinantes: os fertilizantes e as mudas. Os fertilizantes corresponderam com $22,8 \%$ a $25,6 \%$, do total dos custos, do menor para o maior espaçamento, ao passo que, de forma inversa, as mudas proporcionaram a maior amplitude de variação em relação aos insumos, diminuindo de $16,6 \%$, no menor espaçamento, para $5,2 \%$, no maior espaçamento.

O levantamento, de maneira geral, dos custos de produção e preço de venda do maracujá é complexo, pois estes variam de região para região, em razão do nível tecnológico do produtor, do destino da produção (indústria ou fruta fresca), da época do ano, safra ou entressafra (Pires \& São José, 1994). Mas, com relação ao custo de produção, pode-se determiná-lo, estimando-se o volume de frutos necessários para cobrir os gastos com a implantação e condução da cultura, que no presente trabalho variou de $7.978,5 \mathrm{~kg} / \mathrm{ha}$ a $10.070,2 \mathrm{~kg} / \mathrm{ha}$, do maior para o menor espaçamento. Esta relação varia com a produtividade, custos de produção e preço de comercialização. Assim, para produtividades semelhantes ao do presente trabalho, Pires \& São José (1994) citaram ser de $8.573,3 \mathrm{~kg} / \mathrm{ha} / \mathrm{ano}$, com preço de US\$ 0,18 , portanto dentro do intervalo encontrado no presente trabalho. No entanto, em produtividades maiores (30 t/ha), o custo se eleva, aumentando esta relação, que chega a $19.166 \mathrm{~kg} / \mathrm{ha} / \mathrm{ano}$ (Agrianual, 2002). Assim, o aumento da densidade de plantio, que proporciona aumento da produtividade, requer gastos maiores, devendo-se adotar a densidade que proporciona maior relação benefício/ custo (Kits et al., 1996).

A rentabilidade depende também do preço do maracujá, que varia de US\$ 0,10 a US\$ 0,40 para a indústria (Pires \& São José, 1994), e para mercado,

Tabela 2. Avaliação econômica da safrinha de maracujazeiro-amarelo em diferentes densidades de plantio em São Tiago, MG.

\begin{tabular}{|c|c|c|c|c|c|}
\hline \multirow[t]{2}{*}{ Item } & \multicolumn{5}{|c|}{ Plantas/ha } \\
\hline & 3.330 & 2.220 & 1.660 & 1.100 & 830 \\
\hline Custos com insumos ( $\mathrm{R} \$ \mathrm{ha})$ & $2.618,07$ & $2.351,22$ & $2.216,60$ & $2.081,98$ & $2.017,07$ \\
\hline Custo com mecanização (R $\$ / h a)$ & 240,00 & 240,00 & 240,00 & 240,00 & 240,00 \\
\hline Custo com mão-de -obra ( $\mathrm{R} \$ / \mathrm{ha})$ & $1.170,00$ & $1.100,00$ & $1.026,67$ & 950,00 & 934,33 \\
\hline Custo total (R\$/ha) & $4.028,07$ & $3.691,22$ & $3.483,27$ & $3.271,98$ & $3.191,40$ \\
\hline Produção (kg/ha) & 11.722 & 11.944 & 11.236 & 11.743 & 9.282 \\
\hline Custo médio (R\$/kg) & 0,34 & 0,31 & 0,31 & 0,28 & 0,34 \\
\hline Preço pago $(\mathrm{R} \$ / \mathrm{kg})$ & 0,40 & 0,40 & 0,40 & 0,40 & 0,40 \\
\hline Lucro líquido $(\mathrm{R} \$ / \mathrm{ha})$ & 660,81 & $1.086,54$ & $1.011,17$ & $1.425,26$ & 521,56 \\
\hline Relação benefício/custo & 1.16 & 1.29 & 1.29 & 1.44 & 1.16 \\
\hline
\end{tabular}


ao natural, é de US\$ 0,70, média de cinco anos (19972001) nas principais Ceasas do Brasil (Agrianual, 2002). Em São Tiago e região, o preço do fruto para indústria no ano de 2002 foi de R $\$ 0,40$ ou US\$ 0,12 (câmbio de R\$ 1,00:US\$3,50), portanto, próximo ao limite inferior do preço histórico.

\section{Conclusões}

1. O superadensamento não aumenta a produtividade do maracujazeiro-amarelo.

2. A qualidade dos frutos na safrinha não é afetada pelo adensamento de plantio.

3. O adensamento moderado aumenta a eficiência econômica da safrinha.

\section{Agradecimentos}

Ao Sr. Juarez Amaral Viana de Assis, proprietário da fazenda Sant'ana, por ter financiado o projeto; à Capes e ao CNPq, pela concessão de bolsa de estudo aos autores.

\section{Referências}

AGRIANUAL 2000: anuário da agricultura brasileira. São Paulo: FNP Consultoria, 1999. p. 398

AGRIANUAL 2003: anuário da agricultura brasileira. São Paulo: FNP Consultoria, 2002. p. 403-408.

AGUIAR, D. R. D.; SANTOS, C. C. F. Importância econômica e mercado. In: BRUCKNER, C. H.; PIÇANHA, M. C. (Ed.). Maracujá: tecnologia de produção, pós-colheita, agroindústria, mercado. Porto Alegre: Cinco Continentes, 2001. p. 9-32.

ANDRADE, J. M. de B.; BRANDÃO FILHO, J. E. T.; VASCONCELOS, M. A. da S. Efeito da densidade de plantio no primeiro ano de produção do maracujazeiro amarelo, no noroeste do Paraná. Revista Brasileira de Fruticultura, Cruz das Almas, v. 16, n. 2, p. 49-54, set. 1994.

CEREDA, E.; VASCONCELOS, M. A. da S. Influência da densidade de plantio na produtividade do maracujazeiro amarelo (Passiflora edulis Sims. f. flavicarpa Deg.). Revista Brasileira de Fruticultura, Cruz das Almas, v. 13, n. 1, p. 131-135, out. 1991.

FORSHEY, C. G.; ELFVING, D. C. Fruit number, fruit size, and yield relationships in 'McIntosh' apples. Journal of the American Society for Horticultural Science, Alexandria, v. 102, n. 4, p. 399-402, 1977.
IBGE (Rio de Janeiro, RJ). Lavouras permanentes. Disponível em: <www.ibge.gov.br/>. Acesso em: 13 set. 2002.

KITS, H.; FELDENS, A. M.; MANICA, I.; FIORAVANÇO, J. C. Análise econômica de densidades de plantio do maracujá-amarelo no Município de Porto Lucena, RS. Pesquisa Agropecuária Brasileira, Brasília, v. 31, n. 7, p. 497-502, jul. 1996.

LEDERMAN, I. E.; GONZAGA NETO, L.; BEZERRA, J. E. F.; PEDROSA, A. C. Rendimento do maracujazeiro amarelo (Passiflora edulis Sims. f. flavicarpa Deg.) sob diferentes densidades de plantio. In: CONGRESSO BRASILEIRO DE FRUTICULTURA, 8., 1986, Brasília. Anais... Brasília: Sociedade Brasileira de Fruticultura, 1986. p. 397-401.

MANICA, I.; FIORAVANÇO, J. C.; BARRADAS, C. I. N.; KITS, H. Seis espaçamentos de plantio e produção do maracujazeiro-amarelo (Passiflora edulis f. flavicarpa Deg.) em Porto Lucena, RS. Pesquisa Agropecuária Brasileira, Brasília, v. 29, n. 7, p. 10831090, jul. 1994.

MANICA, I.; RITZINGER, R.; MUNDSTOCK, E. C.; MARODIN, G. A. B.; KOLLER, O. C. Efeito de seis espaçamentos de plantio no $2^{\circ}$ ano de produção do maracujá amarelo (Passiflora edulis f. flavicarpa Deg.) em Guaíba/RS. Revista Brasileira de Fruticultura, Cruz das Almas, v. 11, n. 1, p. 25-30, abr. 1989.

MELETTI, L. M. M.; SANTOS, R. R. dos; MINAMI, K. Melhoramento do maracujazeiro-amarelo: obtenção do cultivar 'Composto IAC-27'. Scientia Agricola, Piracicaba, v. 57, n. 3, p. 491-498, jul./set. 2000.

NASCIMENTO, W. M. O.; TOMÉ, A. T.; OLIVEIRA, M. do S. P. de; MULLER, C. H.; CARVALHO, J. E. V. de. Seleção de progênies de maracujazeiro-amarelo (Passiflora edulis f. flavicarpa) quanto à qualidade de frutos. Revista Brasileira de Fruticultura, Jaboticabal, v. 25, n. 1, p. 186-188, abr. 2003.

PACE, C. A. M.; ARAÚJO, C. M. Efeito de densidade de plantio na cultura do maracujá-amarelo (Passiflora edulis f. flavicarpa Deg.). In: CONGRESSO BRASILEIRO DE FRUTICULTURA, 6., 1981, Recife. Anais... Recife: Sociedade Brasileira de Fruticultura, 1981. p. 972-982.

PIRES, M. de M.; SÃO JOSÉ, A. R. Custo de produção e rentabilidade da cultura do maracujazeiro. In: SÃO JOSÉ, A. R. (Ed.). Maracujá: produção e mercado. Vitória da Conquista: UESB, 1994. p. 223-233. 
QUAGGIO, J. A.; PIZA JÚNIOR, C. T. Nutrição e adubação da cultura do maracujá. In: RUGGIERO, C. (Ed.). Maracujá: do plantio à colheita. Jaboticabal: Funep, 1998. p. 130-156.

RITZINGER, R.; MANICA, I.; RIBOLDI, J. Efeito do espaçamento de plantio sobre a produção do maracujáamarelo em Viamão, RS. Pesquisa Agropecuária Brasileira, Brasília, v. 22, n. 8, p. 809-815, ago. 1987.

RUGGIERO, C.; SÃO JOSÉ, A. R.; VOLPE, C. A.; OLIVEIRA， J. C. de; DURIGAN, J. F.; BAUMGARTNER, J. G.; SILVA, J. R. NAKAMURA, K.; FERREIRA, M. E.; KAVATI, R.; PEREIRA, V. de P.
Maracujá para exportação: aspectos técnicos da produção. Brasília: Embrapa-SPI, 1996. 64 p. (Publicações Técnicas FRUPEX, 19).

SÃO JOSÉ, A. R. A cultura do maracujá nas Regiões Norte e Nordeste do Brasil. In: SIMPÓSIO BRASILEIRO SOBRE A CULTURA DO MARACUJAZEIRO, 5., 1998, Jaboticabal. Anais... Jaboticabal: Funep, 1998. p. 3-17.

VASCONCELOS, L. F. L.; ANDRADE, L. T. Efeito do espaçamento na qualidade de frutos da primeira safra de maracujazeiro amarelo cultivado sob condições de irrigação localizada e sequeiro. In: SIMPÓSIO BRASILEIRO SOBRE A CULTURA DO MARACUJAZEIRO, 5., 1998, Jaboticabal. Anais... Jaboticabal: Funep, 1998. p. 326-329. 